\title{
Operating Manual for Water in Hydrocarbon Leak Detector
}

April 1984

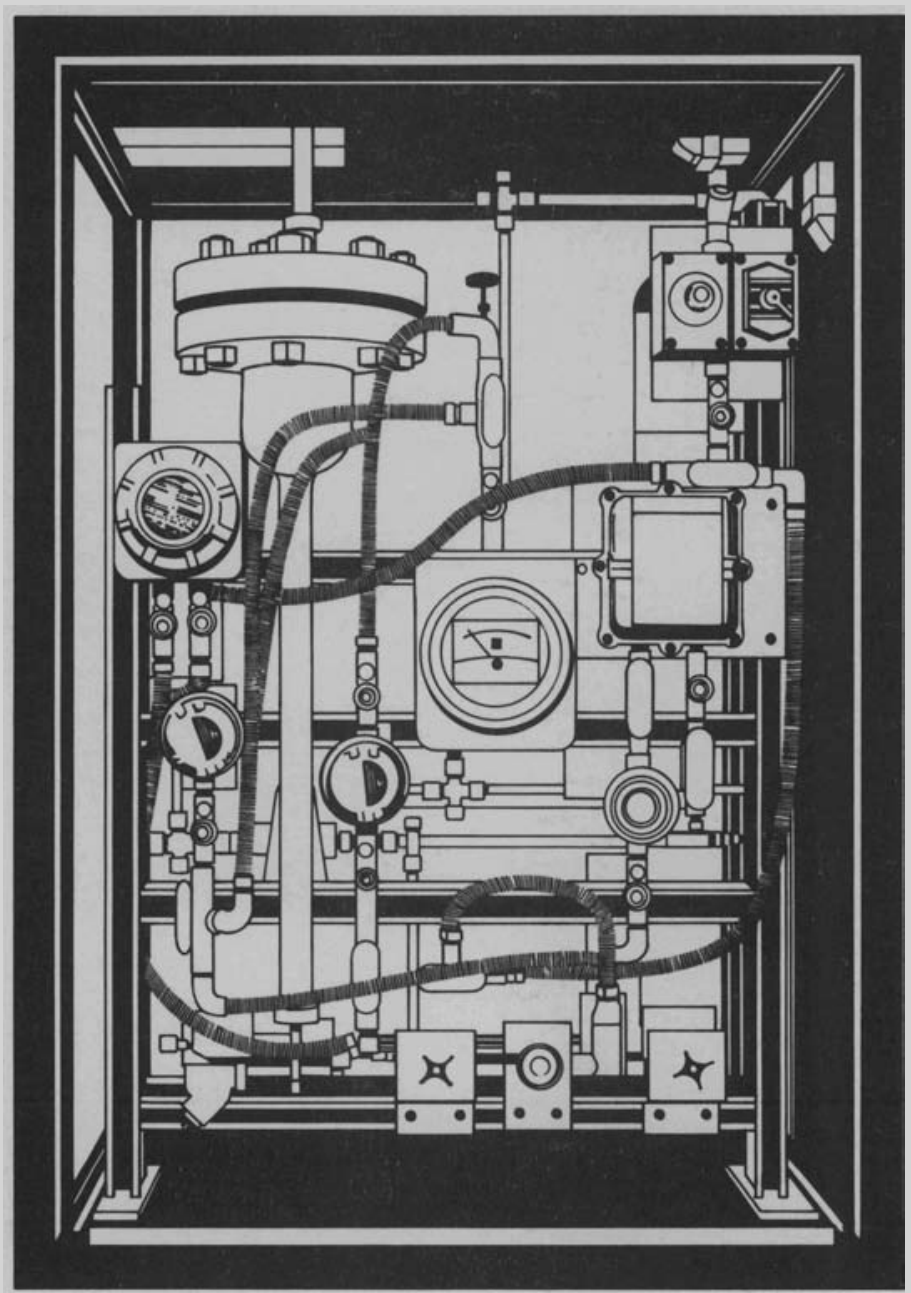

Prepared for the U.S. Department of Energy under Contract DE-AC06-76RLO 1830

Pacific Northwest Laboratory Operated for the U.S. Department of Energy by Battelle Memorial Institute

\section{\%ै: Battelle}




\title{
DISCLAIMER
}

This report was prepared as an account of work sponsored by an agency of the United States Government. Neither the United States Government nor any agency thereof, nor any of their employees, makes any warranty, express or implied, or assumes any legal liability or responsibility for the accuracy, completeness, or usefulness of any information, apparatus, product, or process disclosed, or represents that its use would not infringe privately owned rights. Reference herein to any specific commercial product, process, or service by trade name, trademark, manufacturer, or otherwise, does not necessarily constitute or imply its endorsement, recommendation, or favoring by the United States Government or any agency thereof. The views and opinions of authors expressed herein do not necessarily state or reflect those of the United States Government or any agency thereof.

\author{
PACIFIC NORTHWEST LABORATORY \\ operated by \\ BATTELLE \\ for the \\ UNITED STATES DEPARTMENT OF ENERGY \\ under Contract DE-AC06-76RLO 7830
}


OPERATING MANUAL FOR WATER IN HYDROCARBON LEAK DETECTOR

R. J. Robertus

R.G. Sullivan

D.W. Shannon

April 1984

Prepared for the U.S. Department of Energy under Contract DE-AC06-76RLO 1830

Pacific Northwest Laboratory

Richland, Washington 99352 


\section{TABLE OF CONTENTS}

ONE INTRODUCTION

1.1 Water Detection

1.2 Leak Detection System

1.3 Instrument Features

1.3.1 Flow Monitoring and Control

1.3.2 Water Detection and Measurement

1.3.3 Himmelstein System 6

1.3.4 Solids Filtration System

1.1

- 1.2

- 1.2

- 1.2

- 1.4

- 1.5

- 1.6

TMO INSTALLATION • • • • • . •

2.1 Facility Preparation . . . . . . . . . 2.1

2.2 Installation Drawings . . . . . . . . . . 2.1

2.3 Location and Mounting . . . . . . . . . . 2.2

THREE SET-UP AND CALIBRATION . . . . . . . . . . . 3.1

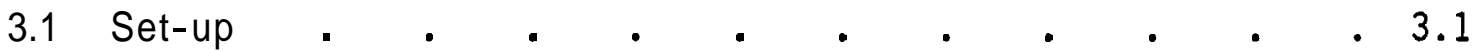

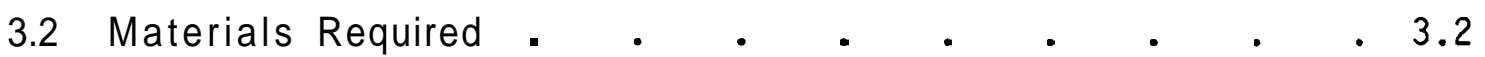

3.3 Setting The Span ( $0 \%$ and 100\% Points) . . . . 3.3

3.4 Setting the "Fill" and "Dump" Points . • . . 3.6

3.5 Correcting For Hydrocarbon Conductivity $\quad$ • . $\quad$ • 3.8

3.6 Connections Between Leak Detector and Counter . . 3.10

3.7 System 6 Counter Setting . • • • • • • . 3.10

3.8 Electronic Counter Checkout . • . . . . . 3.11 
FOUR OPERATION

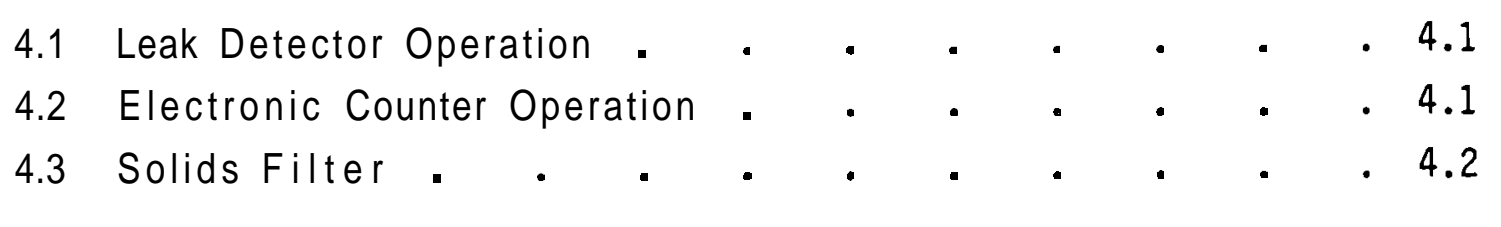

FIVE SERVICE AND MAINTENANCE . $\quad$ • $\quad$ • $\quad$ • $\quad 5.1$

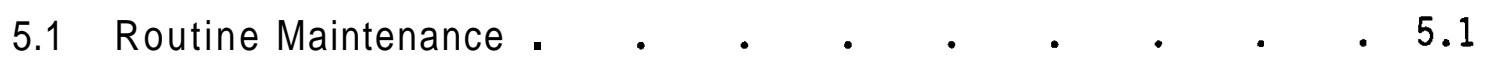

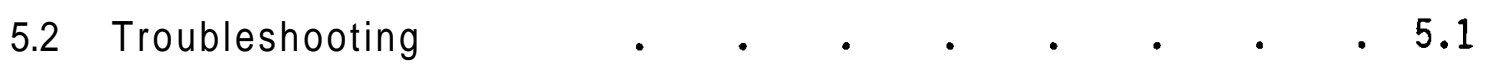

SIX REFERENCE INFORMATION

6.1 Leak Detector Prints . . . . . . . . . . 6.1

6.2 List of Other Manuals . . . . . . . . 6.1 


\section{FIGURES}

Figure No.

Figure 1.1

Figure 2.1

Figure 2.2

Figure 2.4

Figure 3.1

Figure 3.2

Figure 3.3 $\underline{\text { Title }}$

Page

Equipment Flow Diagram.

Recommended Piping to Leak Detector.

Leak Detector Wiring Diagram.

Leak Detector to System 6 Wiring Diagram.

Calibration Setup.

Universal Transmitter Adjustment Knobs.

"Setcon" Adjustments.
2.3

2.4

3.4

1.3

2.2

3.5

3.7 
OPERATING MANUAL FOR WATIR IN

HYDROCARBON LEAK DETECTOR

\subsection{INTRODUCTION}

\subsection{WATER DETECTION}

The leak detector is a prototype instrument which has been calibrated and tested at one geothermal plant site. It is not a production item guaranteed to certain performance standards.

The leak detector when properly installed with appropriate associated equipment will detect the presence of water in a flowing isobutane stream. It gives information so the size of a leak can be estimated at least to an order of magnitude.

The water/isobutane stream must be liquid while flowing through the instrument. Water separates from the isobutane by gravity alone in a large expansion chamber. The separated water collects in an annulus between a 1 1/4-inch pipe and a capacitance probe. The capacitance probe senses when the collection chamber is "full" and actuates a solenoid valve. The solenoid valve allows the collected water to drain. Simultaneous with the actuation of the solenoid valve a mechanical relay is closed. Closing the relay triggers a 3 volt pulse (adjustable from 1 to 5 volts) which is sent to an electronic counter. A second relay actuates a mechanical counter on the instrument. This mechanical count is a running total of the number of times the solenoid valve has opened and drained water.

The detector has been operated over a broad range of hydrocarbon flow rates and water concentrations. It will separate water fom isobutane down to less than 100 ppm H2O. This is close to the solubility of water in isobutane. Over a wide range of operating conditions, the unit recovers $60 \%$ of the water entering the system. 


\subsection{LEAK DETECTION SYSTEM}

A system capable of generating signals for computer monitoring and/or automatic alarming requires an electronic counter as an accessory for the leak detector instrument. A Himmelstein System 6 Pulse Measurement System is included with this first prototype leak detector.

The System 6 is configured to monitor total counts as one channel of information and timed counts as a second channel for each leak detector. (The chosen instrument is easily expandable to monitor three leak detectors). Both channels get input from the 3 volt pulse triggered by opening the solenoid valve. The Total channel keeps track of total counts since the last manual reset or the last power failure. The timed counts is the number of solenoid valve openings which occurred in a pre-set time interval. Only the Total channnel generates a 4-20 ma signal proportional to the number of counts. Both channels can generate alarms as desired by the user.

Once the leak detector is calibrated, the user will know how much water is collected and then dumped when the solenoid valve opens. He will also know the flow of hydrocarbon through the leak detector during operation. 'The System 6 counts the number of dumps. With this information, the user can estimate the size of a leak to at least an order of magnitude. The complete package is not designed to give accurate quantitative information. Its usefulness is in detecting changes from normal operating conditions.

\subsection{INSTRUMENT FEATURES}

Items in this section refer mainly to the leak detector itself. Detailed features of the Himmelstein System 6 are described in separate manuals.

\subsubsection{Flow Monitoring and Control}

A schematic flow diagram for the instrument is shown in Figure 1.1. 


\section{WATER DETECTION AND SOLIDS FILTRATION SYSTEM}

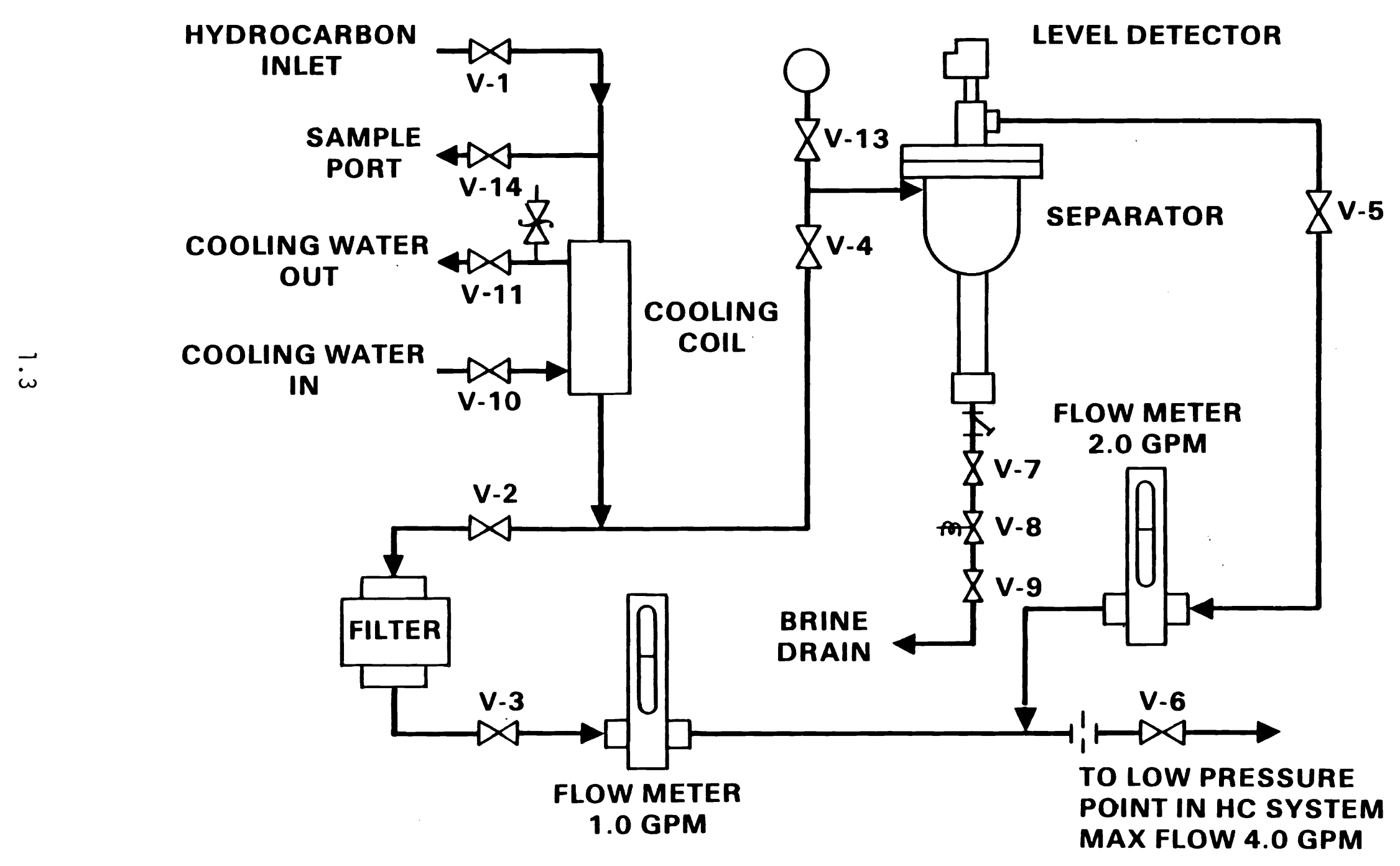

Figure 1.1 Equipment Flow Diagram. 
When necessary, the hydrocarbon stream is first cooled to liquefy it. (Some streams which are liquid already, do not pass through a cooler). The liquid mixture is fed to an expansion chamber where water separates by gravity. A thermocouple at the entrance to the expansion chamber monitors temperature there. Good operating practice says this temperature should be kept fairly constant. Controlling cooling water flow rates is the easiest way to control this temperature. A pressure guage at the inlet to the instrument reads system pressure for the instrument. Knowing temperature and pressure of the system, one can determine if the hydrocarbon is liquid or not.

Flow through the instrument is controlled using manual valves. An armored style rotameter with a magnetic follower is the flow indicator. Flow through the system is not critical but certain ranges are optimal. (Flows greater than $0.2 \mathrm{gpm}$ hydrocarbon but less than $0.7 \mathrm{gpm}$ work quite well). Higher flow rates ( $>1$ gpm hydrocarbon) result in reduced separator efficiency. Low flows allow water to collect in the piping and result in a slugging effect at the collector. This complicates interpretation of the information from the instrument.

Hydrocarbon which is sampled from the plant is returned and re-used in the plant. It is not vented or sent to a sump. Collected water can be combined with the exit hydrocarbon or sent to a sump. The instrument is not meant to be a clean-up device, so no special disposal procedures were developed for the water.

\subsubsection{Water Detection and Measurement}

The instrument detects water because it is a much better electrical conductor than liquid hydrocarbon. Water which is separated from the hydrocarbon collects in an annulus formed by a capacitance probe inside a pipe. The capacitance probe shows readings between 0 and $100 \%$ as the annulus fills with water. The $100 \%$ and $0 \%$ points are arbitrary and user adjustable at the universal transmitter. 
The setcon controller determines the volume of liquid which is dumped when the solenoid valve is opened. The dumped volume is always less than or at most equal to the collected volume. The "open" and "close" settings for the solenoid valve are set at some percentage value associated with the scale set by the universal transmitter. As an example one could choose to dump when the chamber was $75 \%$ full then start refilling when the annulus was still 10\%full. Choosing values other than 0 and $100 \%$ alleviates problems associated with overshoots if the system is dumping 'and filling rapidly. When the system reaches its "dump" set point, the solenoid valve opens. This advances a mechanical counter $1 / 2$ count. Simultaneously it actuates a relay which closes a circuit to send a 3 volt pulse to an electronic counter. When the water has emptied to the "fill"set point, the solenoid valve closes and the mechanical counter advances another $1 / 2$ count. This feature of moving $1 / 2$ count at actuation and a second $1 / 2$ count at de-actuation is useful during debugging to tell where the system is in its cycle.

\subsubsection{Himmelstein System 6}

This commercially available electronic counter was purchased to provide interface information for a process computer and operating alarms. The System 6 accepts a 1 to 5 volt d.c. pulse input and sends out a 4-20 ma signal proportional to the total number of pulses it receives. The signal is generated by closing of a mechanical relay whenever the solenoid drain valve opens. This mechanical closure can generate enough electrical noise to cause multiple counts. A simple resistance-capacitance filter is installed on the inlet signal line to minimize the noise problem. The 3 volt signal recommended for this configuration is generated by a solid state regulated power supply which is powered continuously. Only its 3 -volt output is turned on and off.

The System 6 has:

One 6-138 A/D Converter with rack mount adapters

One 6-405B Scanner

One 6-305 Timer 
Two 6-317 Digital Totalizers

One 6-702A Dual Digit Limit

One 6-770.1 D/A Converter with channel 1 4-20 MA option

Each leak detector connected to the System 6 uses two totalizers a timer, a dual digit limit and a D/A converter. One totalizer counts total number of dumps from the previous manually re-set time. An alarm can be set off this totalizer. A second totalizer monitors number of dumps in a user selected time interval. It also has an associated alarm. The alarm settings and time interval are user selectable.

Total counts give indications of long term leakage rates. The timed counts track transients which might occur during start-up and shut-down of a plant.

If the hydrocarbon does get contaminated during a shut down, this leak detection system can be used to monitor effectiveness of any clean-up procedures too. As the system gets cleaner, the number of counts per day will decrease to some steady-state point (hopefully zero).

\subsubsection{Solids Filtration System}

The leak detector contains a filter housing through which hydrocarbon can be routed. The housing is pressure rated and uses a single filter $47 \mathrm{~mm}$ in diameter. A separate flow meter is located in the filter loop so hydrocarbon rates through the filter can be set.

Normally the filter is not used. It has been added to the system so solids samples can be collected when desired. 


\subsection{NSTALATION}

\subsection{FACILITY PREPARATION}

Installation of the leak detector requires one hydrocarbon inlet line, one hydrocarbon outlet line and a drain line for collected water. The pressure differential between hydrocarbon inlet and outlet lines should be $10 \mathrm{psi}$ or more. (The system was checked at pressure differentials in excess of 25 psi and worked well. Too low a differential pressure could mean flows below $0.2 \mathrm{gpm}$. Then the unit would not operate satisfactorily). The water drain line could be tied back into the hydrocarbon return line. For locations sampling hydrocarbon vapor, cooling water must be supplied to the built-in heat exchanger on the leak detector. A cooling water return line is also required.

Electrical requirements are a single nominal 120 VAC 15 amp line to the unit and a low voltage two-wire conductor out of the instrument. The low voltage wire carries the pulse signal from the solenoid valve relay to the electronic counter.

\subsection{NSTALATION DRAWNGS}

All piping connections are typically $1 / 2$ inch tubing and screw into 3/8 inch NPT valves in the leak detector. Shut-off valves should be installed on all lines so the instrument can be isolated for maintenance. A recommended configuration is shown in Figure 2.1.

The 120 VAC for the instrument is hard wired to an on-off switch with a pilot light. A wiring diagram for the unit is shown in Figure 2.2. Connections between the leak detector, the 1-5 VDC power supply and the electronic counter are shown in Figure 2.3. 


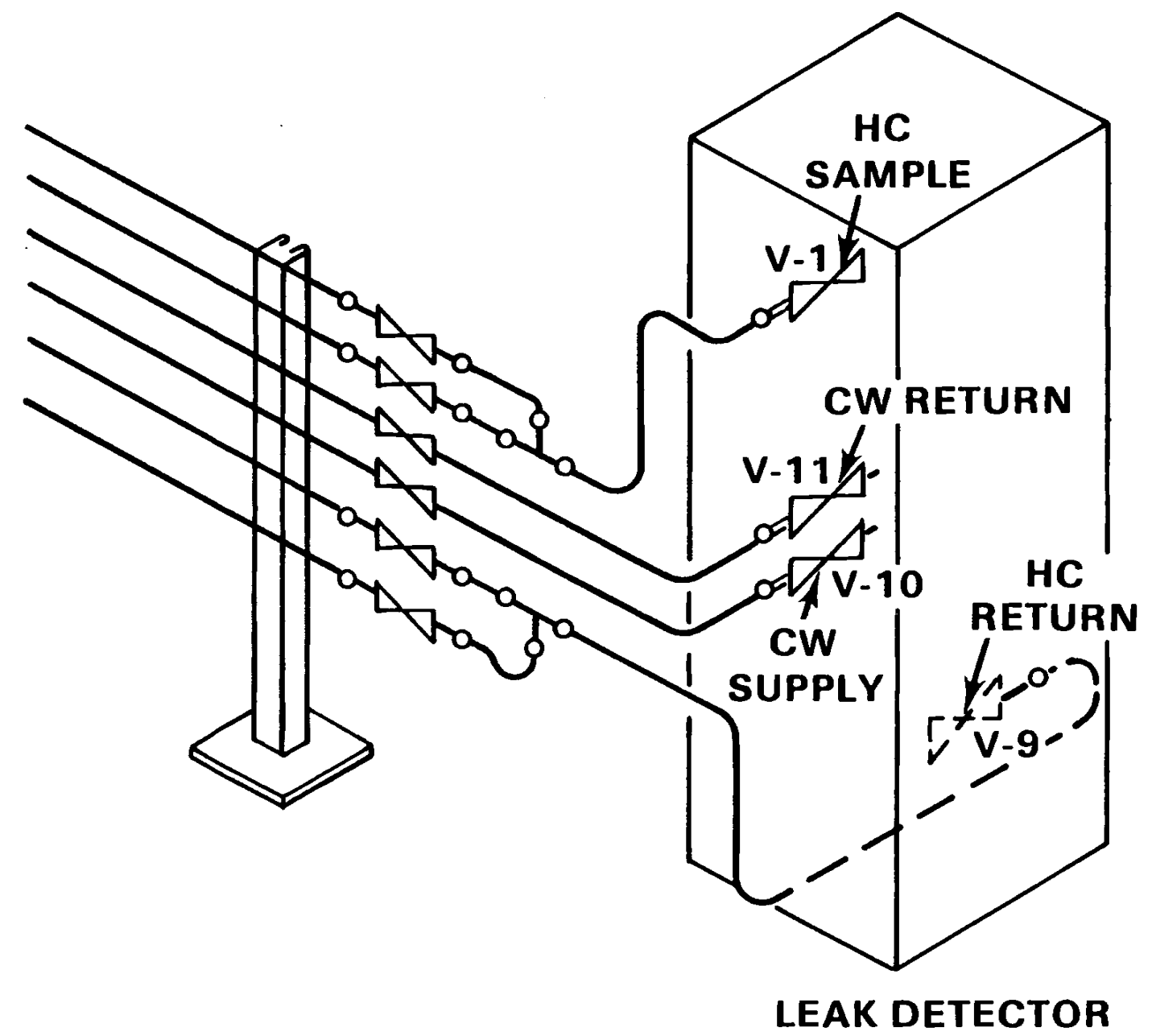

Figure 2.1 Recommended Piping to eak Detector 


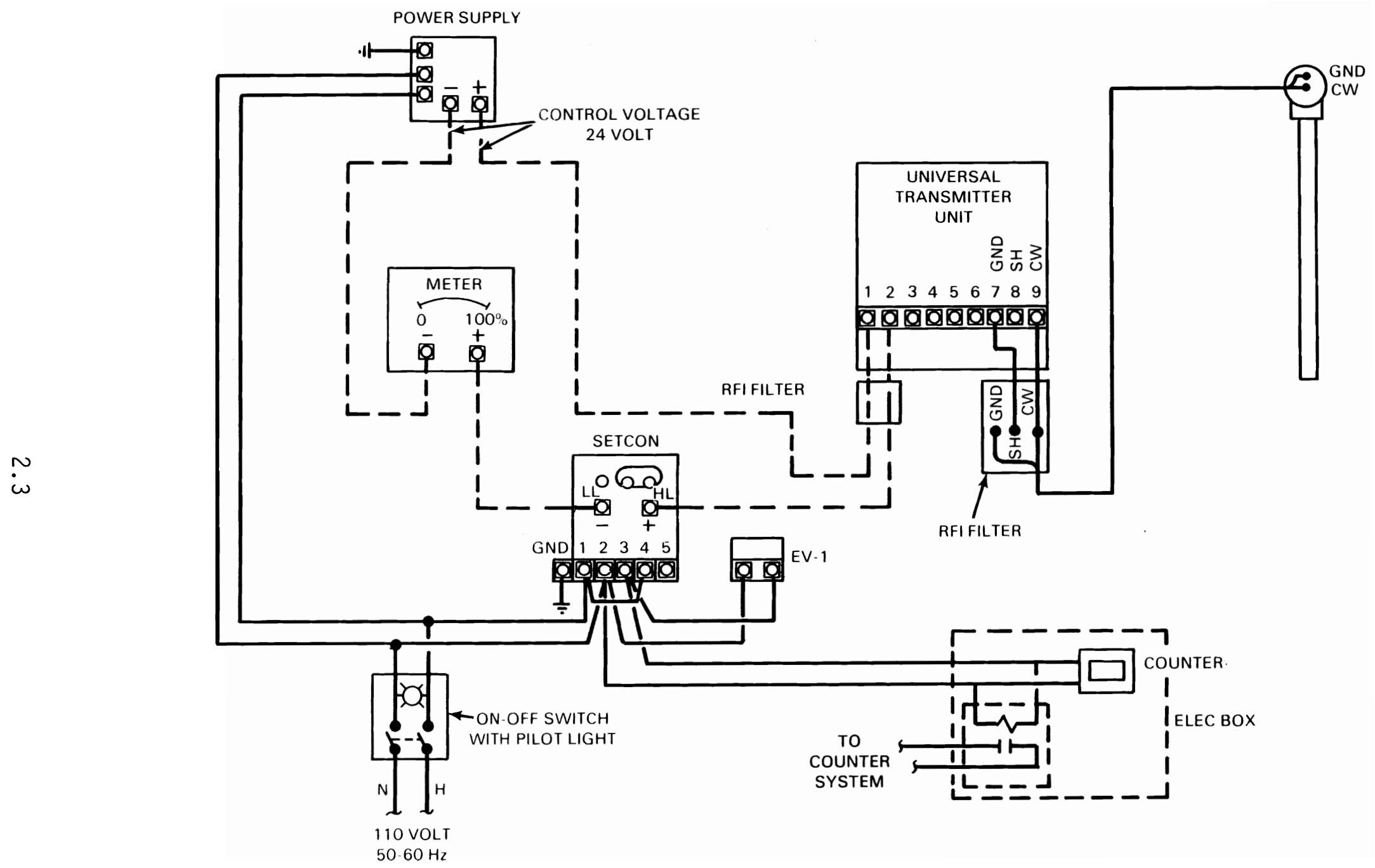

Figure Leak Detector Wiring Diagram. 


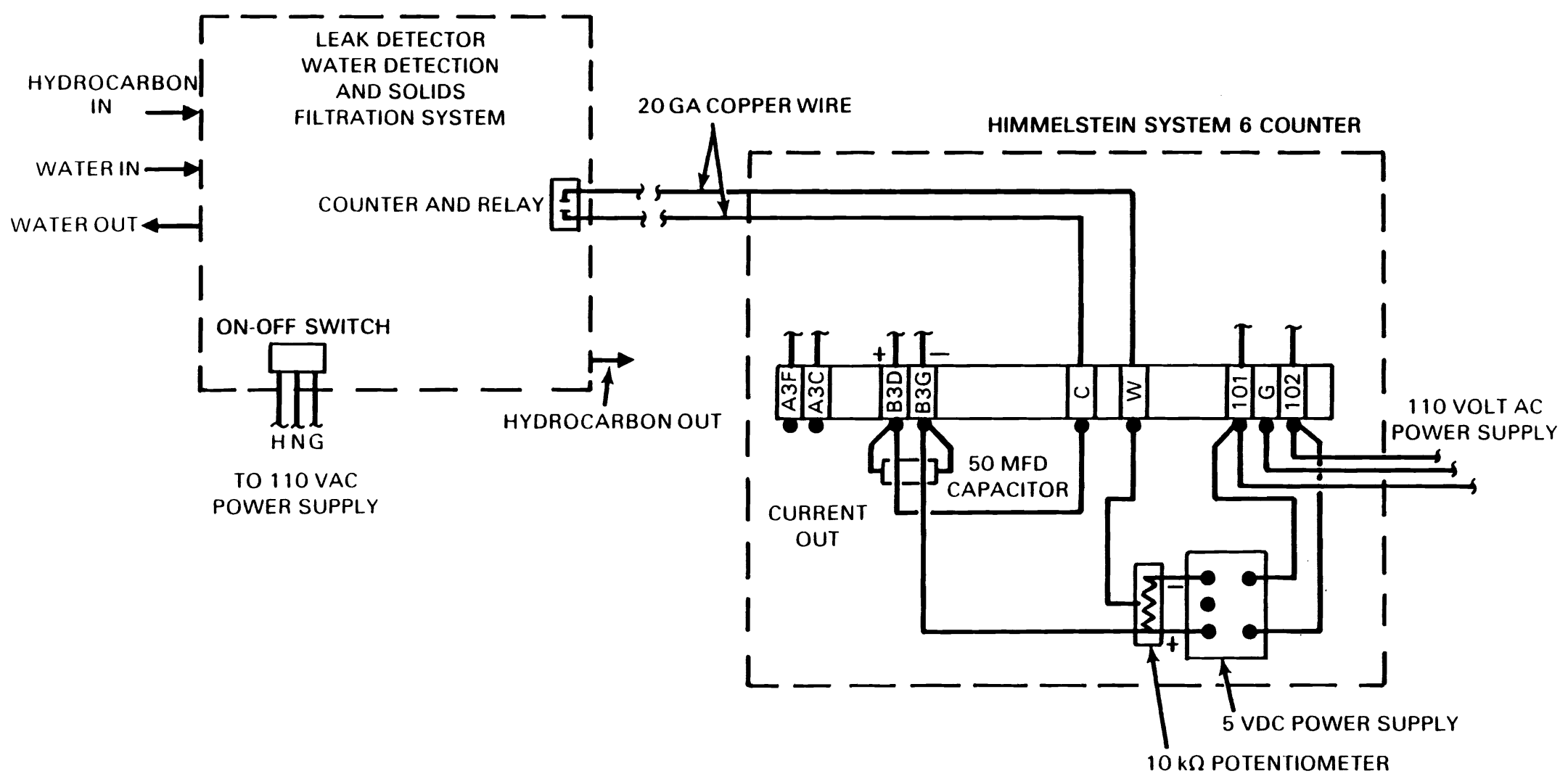

Figure 2.3 eak Detector to System 6 Wiring Diagram. 


\subsection{LOCATION AND MOUNTING}

The leak detector comes in a paneled framework for installation outdoors. It can be mounted wherever is convenient. Bolting it to a a concrete pad would be ideal. It can be supported above grade provided the structure strength is sufficient to hold the 500 pound weight of the package. The units dimensions are 40 " wide by 36 " deep by 60" high. A minimum of 3 feet clearance on all sides is desirable for maintenance reasons.

The electronic counter should be panel mounted indoors. It fits in a standard instrument rack 19 inches wide. The front panel should be 10 inches high. The maximum depth of any of the components is 20 inches. 


\subsection{SET-UP AND CALIBRATION}

\subsection{SET-UP}

Set-up consists of setting $0 \%$ and $100 \%$ locations using the universal transmitter then choosing and setting "fill" and "dump" points using the setcon. The recommended initial set points given in Table 3.1 are based on field tests at a geothermal power plant. They are not guaranteed to be the best choices for the Heber plant. They did give reliable information over a broad range of test conditions.

Table 3.1 Recommended Initial Leak Detector Settings

1. $0 \%$ point in water and air ... 13" above bottom of collection tube.

2. $100 \%$ point for water and air ... 33" above bottom of collection tube.

3. "fill" point ... 15\% on Drexelbrook meter.

4. "dump" point ... 60\% on Drexelbrook meter.

5. Electrical signal from leak detector to System $6 \ldots-3$ volts dc.

6. Channel 1 Totalizer count on System 6 ... 1999 before resetting.

7. Channel 2 Timed counts ... 999 before resetting.

8. Time interval before resetting Channel $2 \ldots 1$ hour.

\subsection{MATERIALS REQUIRED}

The four set points mentioned above can be adjusted at ambient pressure using a

- four-foot section of $1 / 4$-inch tygon tubing,

- Parker style $1 / 2^{\prime \prime}$ tee fitting with $1 / 2^{\prime \prime}$ metering valve attached to one leg, 
- 5 gallon carboy of water,

- tape measure,

- stop watch, and

- 500 cc graduated cylinder.

Calibration of the percent scale on the level meter is best done under pressure. This requires:

- a high pressure pump* for injecting liquid $(1.5 \mathrm{ml} / \mathrm{min}$ at 1000 psi capacity), and

- another tee and valve assembly at the inlet to the separator vessel.

Techniques have been developed to verify the separation efficiency of the instrument. "According to R.J. Robertus of Pacific Northwest Laboratory, they are lengthy and really need not be done unless hydrocarbon flows for some 'reason must fall outside the 0.2 to $0.7 \mathrm{gpm}$ range. "Within this range the separation efficiency is approximately $60 \%$. i.e. $60 \%$ of the water passing into the system is separated and collected.

${ }^{*}$ One successfully tested pump is an Eldex Model A-30-S $(90 \mathrm{ml} / \mathrm{hr}$ capacity) built by Eldex Laboratories, Mento Park, California. 


\subsection{SETTING THE SPAN (0\% and $100 \%$ POINTS)}

Refer to Figure 3.1 for mechanical setup and Figure 3.2 for the Universal Transmitter's adjustment locations.

a) Be sure the leak detector is isolated from the plant and is at 0 psig.

b) Disconnect the drain line on the water collection tube and attach the tygon tubing to one leg of a tee fitting. (A metering valve should be attached to the second horizontal leg).

c) Attach the tygon tubing to the vessel so it can be used as a level indicating sight glass.

d) Set the Step Span on the Universal Transmitter to position 1. Set the Fine Span to extreme clockwise position.

e) Fill the vessel to a level 13 inches above the outside bottom edge of the collection tube.

f) Adjust the Step and Fine Zero controls on the Universal Transmitter until the output is a minimum. ( $0 \%$ on the Drexelbrook meter).

g) Fill the vessel to 33" above the bottom of the collection tube. Output on the meter will exceed $100 \%$.

h) Turn the Step Span control clockwise until the output is less than full scale, then back off Step Span one position.

i) Turn the Fine Span control until the meter reads exactly $100 \%$.

The span settings are complete. Record the controller settings which gave the $0 \%$ and $100 \%$ readings. 


\section{CALIBRATION SETUP}

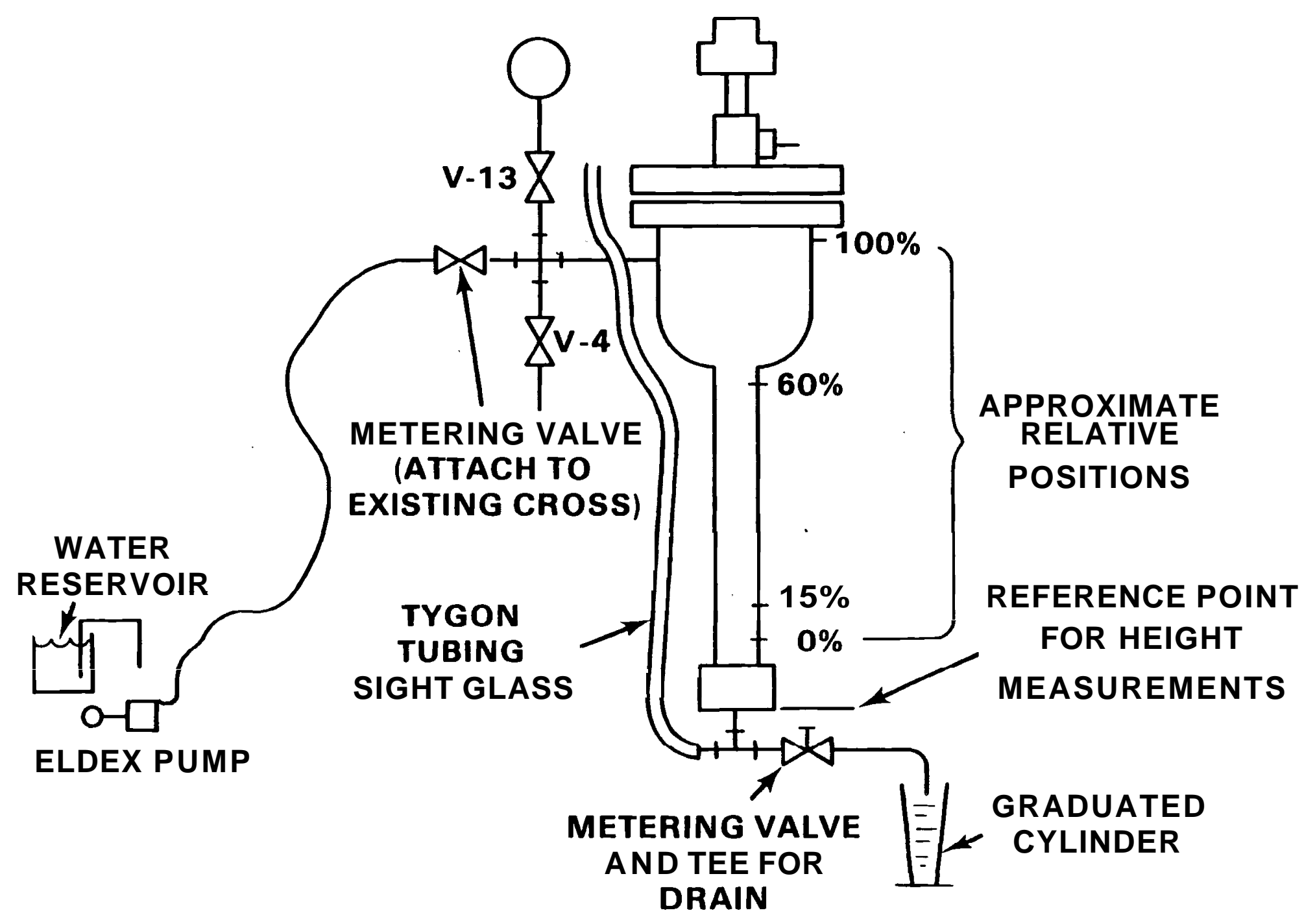




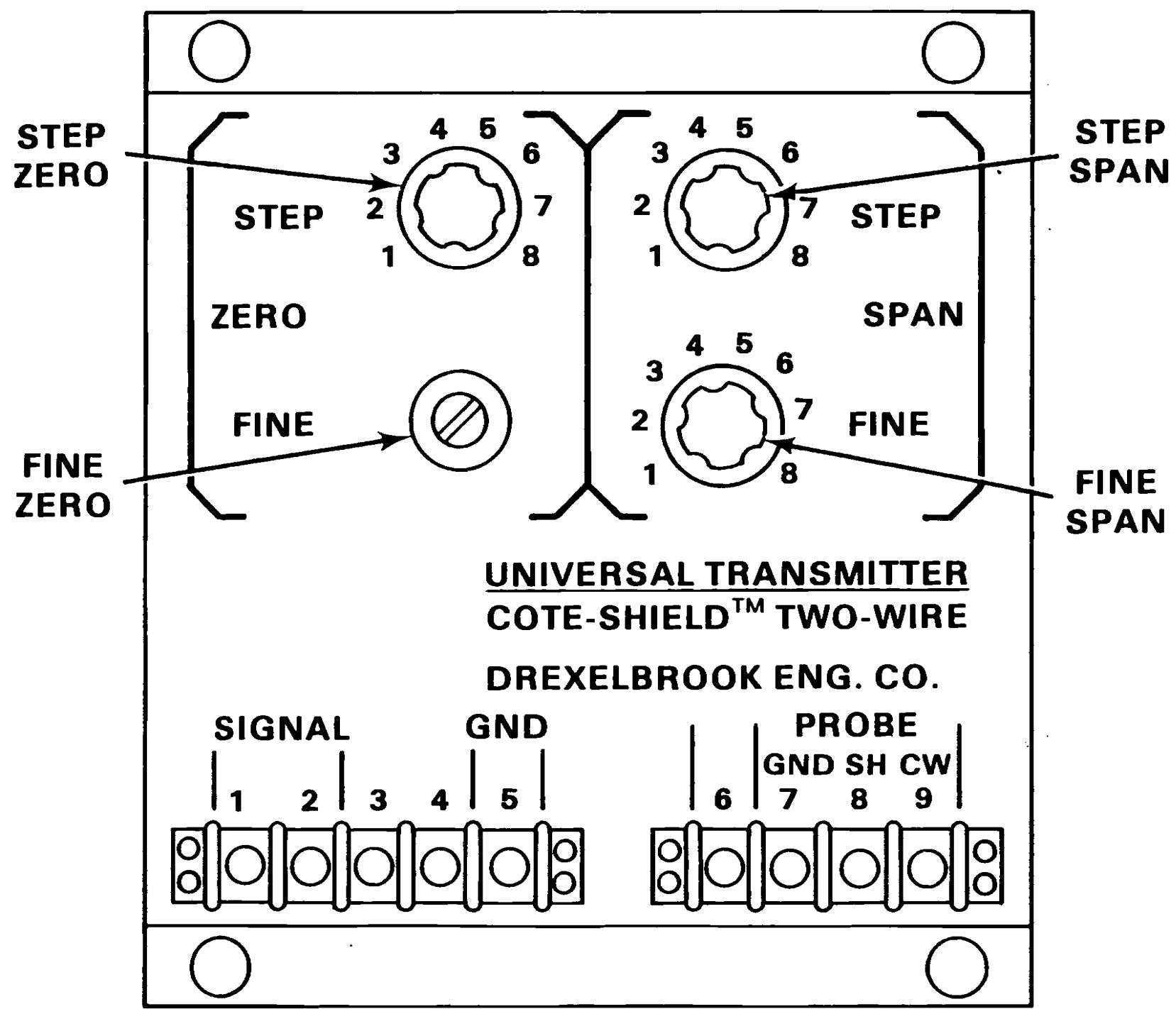

Figure 3.2 Universal Transmitter Adjustment Knobs. 


\subsection{SETTING THE "FILL" AND "DUMP" POINTS}

This procedure may require several fillings of the collection tube to get both end points where desired. The "fill" point closes the solenoid valve and the tube starts filling. The "dump" point opens the solenoid valve to drain the vessel.

Figure 3.3 shows controls for set point adjustment and differential adjustment.

OBSERVE: Because of the way the controller is configured, one must always drain below the "dump" point before changing settings on the setcon.

The volume of water dumped per cycle is arbitrary but should fall in the range of 80 to $150 \mathrm{cc}$. The "dump" point is also arbitrary but should be where the liquid level is still in the collection tube as opposed to somewhere in the separation chamber.

a) Close valve V-9 on the outlet of the leak detector to prevent water draining there.

b) Turn the Differential Adjustment pot (deadband pot) to full counter-clockwise (ccw) position.

c) Fill the collection tube to $60 \%$ on the Drexelbrook meter. (Water should be close to 25" above the bottom of the collection tube). .

d) Adjust the Set Point knob on the setcon until the solenoid valve just opens to this level. (Water should not drain at this point but the noise of the solenoid can be heard. Also the mechanical counter should advance $1 / 2$ count).

e) Turn the differential adjustment pot to full clockwise (cw) position. 


\section{"SETCON" SETPOINT CONTROL}

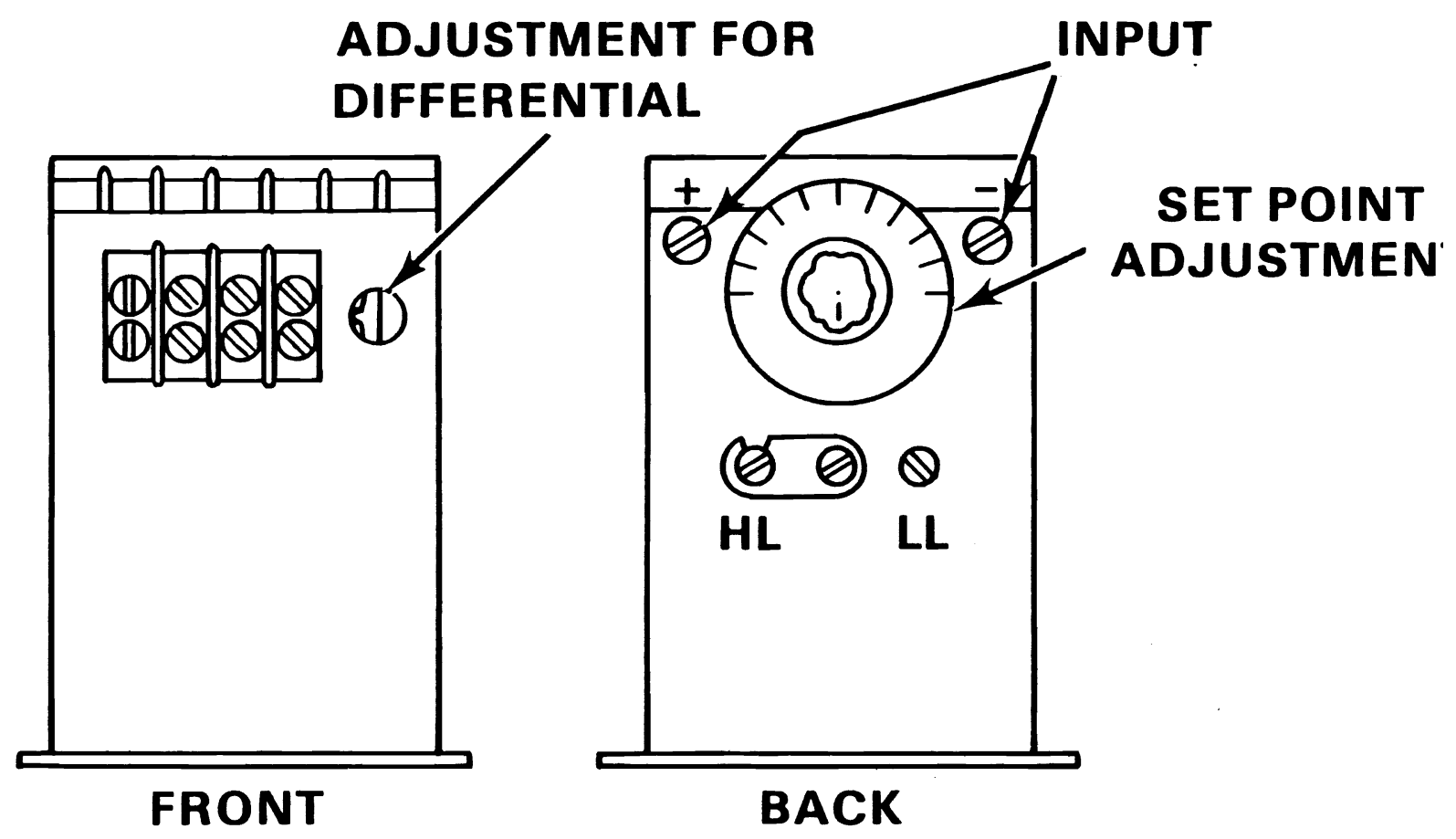


f) Open the small metering valve installed at the bottom of the collection tube. Slowly drain the water into a $500 \mathrm{cc}$ cylinder until the Drexelbrook meter reads 15\%. (Water level should be close to 16" above the bottom of the collection tube).

g) Slowly turn the Differential Adjustment Pot ccw until the solenoid valve just closes and the mechanical counter advances another $1 / 2$ count.

h) Open valve V-9 and close the small metering valve.

i) Slowly fill the vessel again and record the \% readings when the solenoid valve opens and closes.

When the $0 \%$ and $100 \%$ points are set as recommended, a $1 \%$ change in scale reading will be between 2 and $2.5 \mathrm{cc}$ of water in the collection tube. (The number changes rapidly if the dump point falls in the bowl of the separator). When the setcon is adjusted as suggested, about 100 cc of water will drain on each dump cycle. Once set, the dump volume is reliably constant (within 5\%) over many cycles.

Record actual settings used for future reference.

\subsection{CORRECTING FOR HMDROCAPBON CONDUCTIVITY}

The settings established above in the air-water environment will be satisfactory for purely qualitative indications of leaks. They will also suffice for detecting relative changes from one day to the next. If semi-quantitative information is desired, the above procedure must be followed by a high pressure check of the set points.

The conductivity of isobutane is much lower than water but much higher than air. Thus when the collection tube is filled with isobutane and water instead of air and water, the capacitance readings (on the \% scale) will change. 
The following procedure usually has to be repeated more than once. Repeating it requires leaving the system at pressure and injecting water using a high pressure pump. This requires installation of another tee and valve assembly at the inlet to the separation vessel, i.e. downstream of valve $\mathrm{V}-4$. The valve and tee should be installed before step a) below is started. They can be left in place during plant operation. Then future attempts to inject water would not require venting the leak detector.

Procedure

a) Disconnect the tygon tubing but leave the metering valve on the bottom of the collection vessel.

b) Keep the water drain valve V-9 closed.

c) Fill the collection tube to $1 \%$ above the point where the solenoid valve opens.

d) Fill the detector with liquid hydrocarbon. Flow until the inlet to the separation chamber is $60^{\circ} \mathrm{C}\left(140^{\circ} \mathrm{F}\right)$ but not longer than 15 minutes.

e) Shut the outlet valve $(V-6)$ to the system but leave the inlet valves ( $\mathrm{V}-1$ and $\mathrm{V}-4$ open).

f) Note the new \% reading with the collection tube ready to dump and with isobutane in the system.

g) Slowly drain the water into a $500 \mathrm{cc}$ graduated cylinder using the metering valve. Record a few points during the drain cycle.

h) Listen carefully for the solenoid valve when it clicks closed (and the mechanical counter advances). Water collected at this point will be the actual volume dumped for one cycle during operation. (*** It will NOT be the same volume collected under ambient conditions $\left.{ }^{* * *}\right)$. 
i) Drain the collection tube completely of water. USE EXIREME CAUTION to avoid hydrocarbon spattering.

j) Close the metering valve and record the new zero point (It should show $30-35 \%$ on the meter).

The scale is linear for the instrument so one can now calculate the volume of liquid being collected with each \% change in the meter reading when the system is pressurized.

NOTE: There are some indications that the temperature of the hydrocarbon will affect the $\%$ readings slightly. Thus for accurate determination of water collected over a period of time, one must maintain the hydrocarbon temperature constant.

\subsection{CONNECTIONS BETWEEN LEAK DEIECTOR AND COUNIER}

Physically the power supply used to generate the 3 -volt dc pulse for the counter is in the counter cabinet. A wiring diagram showing relationship of the power supply to the counter and the relay in the leak detector was shown in Figure 2.3.

\subsection{SYSTEM 6 COUNIER SETTING}

All settings on the electronics counter should be done in accordance with manuals supplied by S. Himmelstein and Company. The maximum counts (number which gives a 20 ma output signal) for each totalizer is user selectable using push buttons on the front of the instrument. A timer exists for each totalizer that is to be reset at some interval. That timed interval is selected using internal switches on a circuit board.

Recommended initial settings were given in Table 3.1. 


\subsection{EUECIRONIC COUNTER CHECKOUT}

To verify that the counter does indeed count relay closures:

a) connect a pair of leads from the 3 volt power supply to the input lugs for counter being tested.

b) break one lead and connect a push button switch in the circuit.

c) manually trigger the switch several times and verify the counts detected by the System 6 .

d) if no counts are recorded, first check to see that the 3-volt signal exists. If it does, refer to the Himmelstein manuals for further checks. 


\subsection{OPERATION}

Both the leak detector and the System 6 counter are expected to run continuously with 1ittle attention.

\subsection{LEAK DEIECTOR OPERATION}

Once the leak detector is installed it should be checked daily. The two important variables are temperature of fluid into the separator and flow of hydrocarbon through the system.

Temperature can be checked using a portable readout for type $\mathrm{K}$ thermocouples (such as a Fluke handheld digital voltmeter with thermocouple accessory). It should be maintained close to $60^{\circ} \mathrm{C}\left(140^{\circ} \mathrm{F}\right)$. Adjustments are made by changing the cooling water flow through the heat exchanger.

Flow of hydrocarbon should be set at 0.4 on the rotameter scale. (0.5 $\mathrm{gpm} \mathrm{iC4).} \mathrm{It} \mathrm{is} \mathrm{adjusted} \mathrm{using} \mathrm{valve} V-6$ for normal operation. Valve $V-5$ should be used if the solids filter is being used simultaneously.

\subsection{ELECTRONIC COUNIER OPERATION}

Detailed operating instructions are given in manuals supplied by Himmelstein. The unit is presently set to give a 4-20 ma signal of $f$ channel 1 when counts vary between 0 and 1999, i.e. 0 counts $=4 \mathrm{ma}$ and 1999 counts $=20 \mathrm{ma}$. This is the total count. The timed count varies between 0 and 999 . These ranges can be changed with push buttons on the front panel. The counter is programmed to re-zero itself every 3600 seconds. That value is set using switches on the circuit board for the timer module. Alarm settings are dialed on the front panel and not set to any pertinent value now. 


\subsection{SOLDS FLTER}

The filter housing can be isolated using valves V-2 and V-3 while the rest of the unit is in operation. However, a safer practice is to isolate the entire leak detector prior to inserting or removing a filter. The filter should be $47 \mathrm{~mm}$ in diameter and of whatever particle size that is to be collected. Gelman Company makes satisfactory filters.

Normal operation is with the filter by-passed. When the filter is to be used for only a short time (a few hours), it is recommended all the flow be diverted through it. For longer range sampling flow can be split between the leak detector and the filter. Balancing flows between the two systems is not difficult, but will require frequent checking by operators; probably once per shift as a minimum. 


\subsection{SERVICE AND MAINTENANCE}

\subsection{ROUTINE MAINTENANCE}

The most important check of the system is to be sure the instrument will collect and dump water. If no water has been collected for some time, it is recommended that water be injected into the feed line while the instrument is operating. The water should be injected using the Eldex pump and injection location recommended in the CALIBRATION section. (The pump's capacity was $90 \mathrm{ml} /$ hour). It may take 5-8 hours to verify that the system collects water and counts properly. This check should be run at least quarterly.

The leak detector itself requires periodic checking of valve packing. It is recommended that all packing glands be checked and tightened as appropriate at least once per month.

No routine maintenance is required on the Himmelstein System 6.

\section{$5.2 \quad$ TROUBLE-SHOOTING}

The following guide is likely not comprehensive. The unit is new enough that few problems have been encountered. Several of the problems listed have never occurred so the recommended solutions are best guesses. More operating experience is necessary to define real problems and cures.

Some of the cures suggested in Table 5.1 require rather involved procedures. Any valve repair will require isolating and venting the leak detector. Details are not provided. Common sense and safety consciousness should guide any workers. 
Table 5.1 TROUBLESHOOTING GUIDE

MALFUNCTION

1. NO COUNTS

no flow or low flow

(2)

meter reading $100 \%$

meter stays below

"fill" setting

capacitance meter not working

3-volt power supply not working

relay in leak detector not working

open or shorted leads

from leak detector

System 6 malfunction

2. MULTIPLE COUNTS

relay malfunction bad capacitor on input line

line noise from plant

insufficient pressure drop across detector

rotameter stuck

water drain line plugged

solenoid valve stuck/plugged

solenoid stuck open

solenoid not seating

internal electrical damage

probe element corroded through

internal damage

dirty contacts

broken unit

cable damage

unknown

dirty/broken contacts unknown

large motors ydrocarbon flow too low

hydrocarbon temperature too high

3. UNSTABLE MEIER READINGS slugging water flow

cooling water flow too low
POSSIBLE QRE

clean strainer

open full then

close to jar plug

Toose

vary flows over wide range to free

float

disassemble \&

clean

check with plant

operators to

increase

open inlet \&

outlet valves more

open V-9 full open

to jar loose

remove line \& clean

turn power on \& off

to cycle valve

remove valve,

clean seats.

replace if

necessary

remove solenoid and/or valve \&

clean

increase DP across

it

clean seats

replace seats

see separate manual

remove/inspect/

replace as needed

replace

clean

replace

replace

check other manuals

clean or replace

replace

design better signal filter...

consult

Himmelstein

increase

increase 


\subsection{REFERENCE INFORMATION}

\subsection{LEAK DEIECTOR PRINTS}

The following prints are enclosed:

Water Detection and Solids Filtration System. Drawing \#SK-26406 sheets 1 through 5 . 


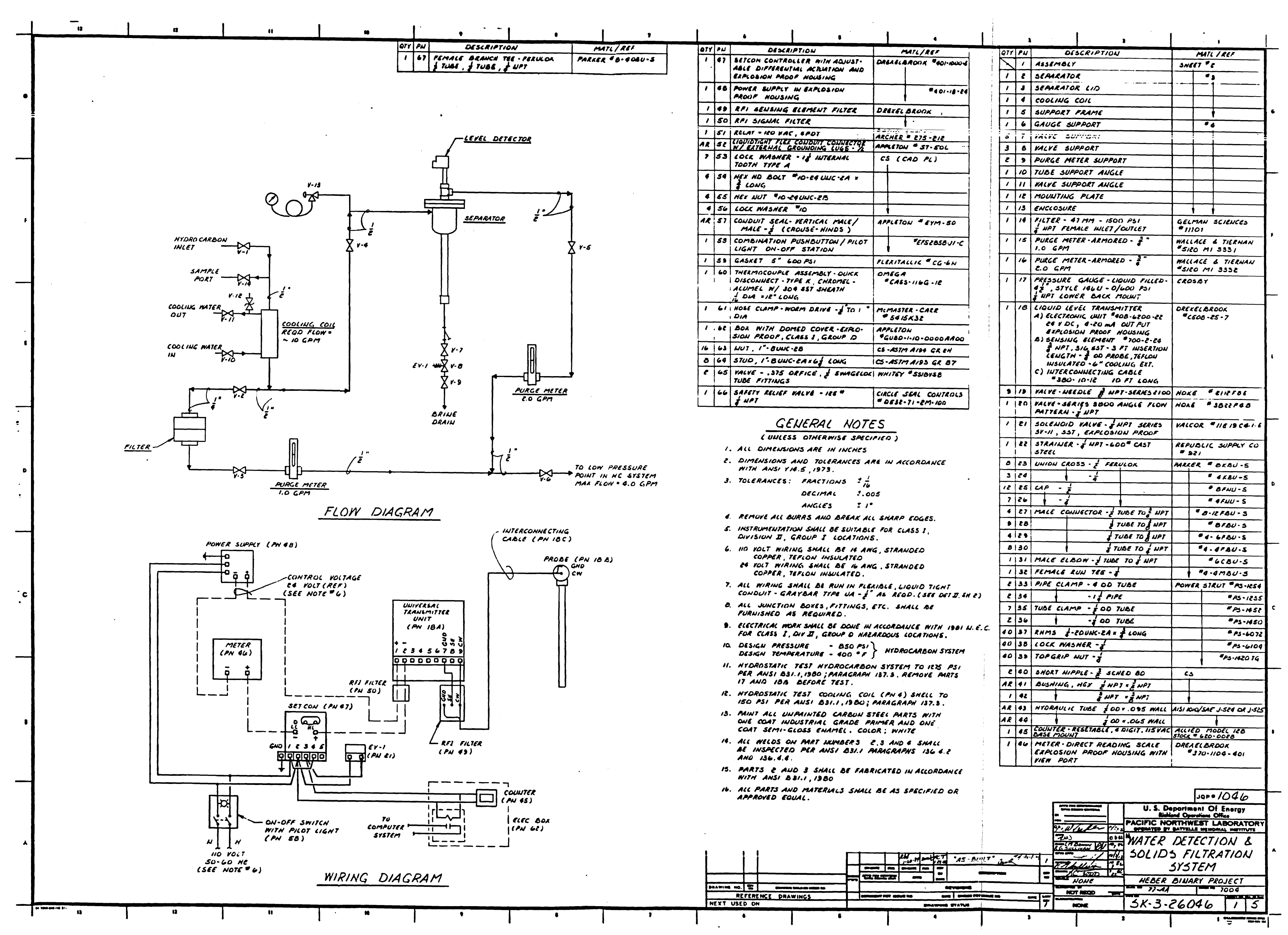




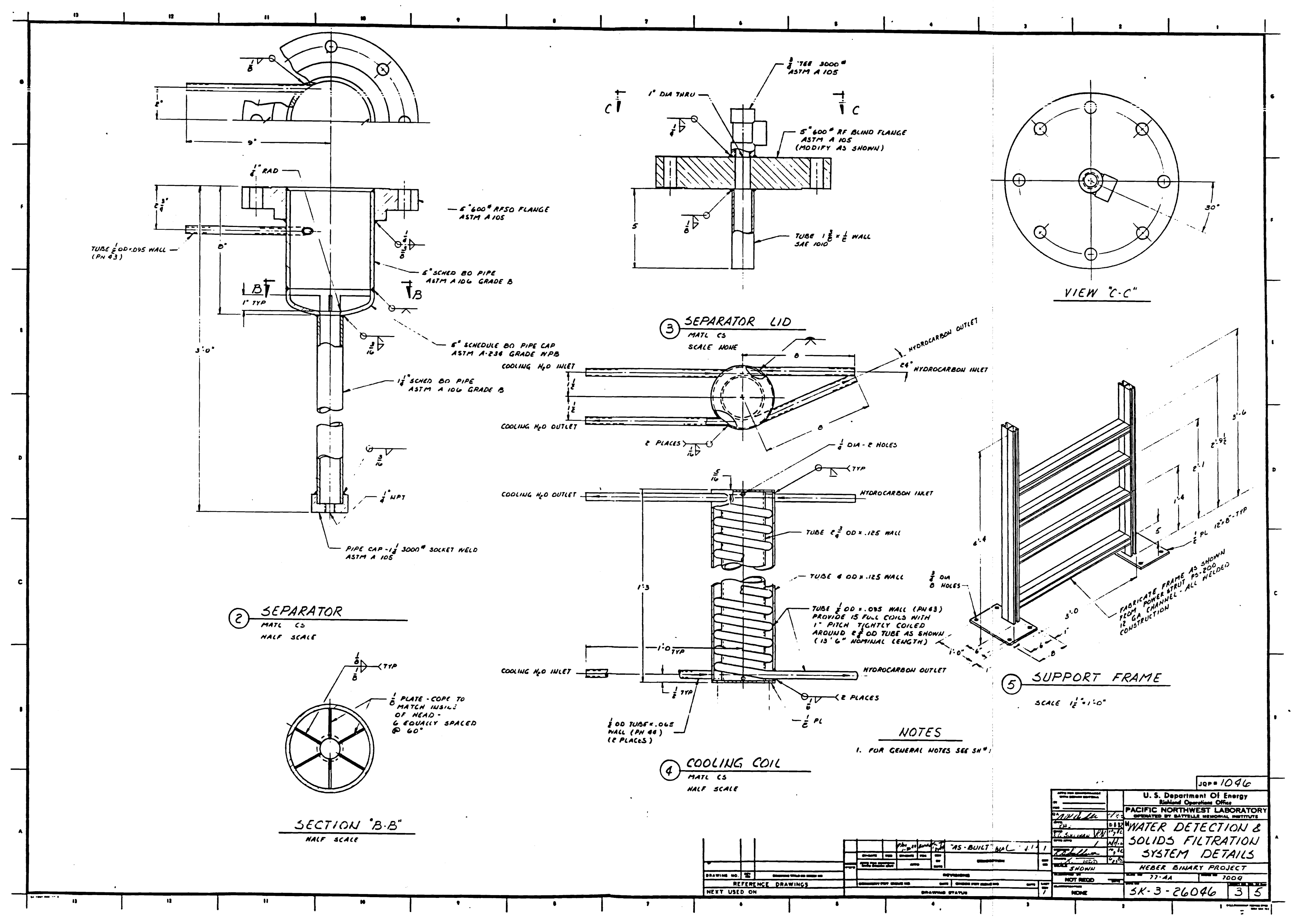




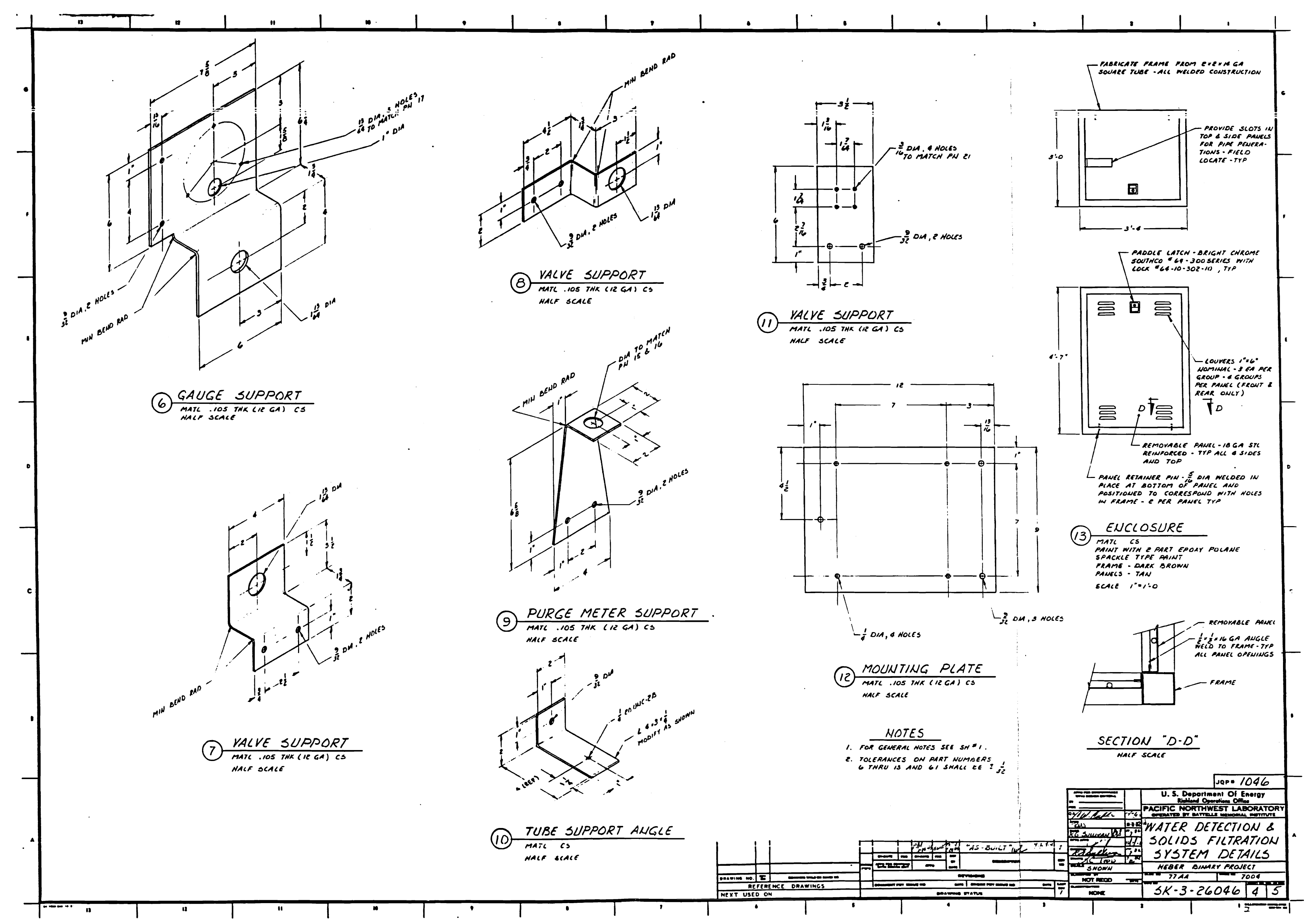




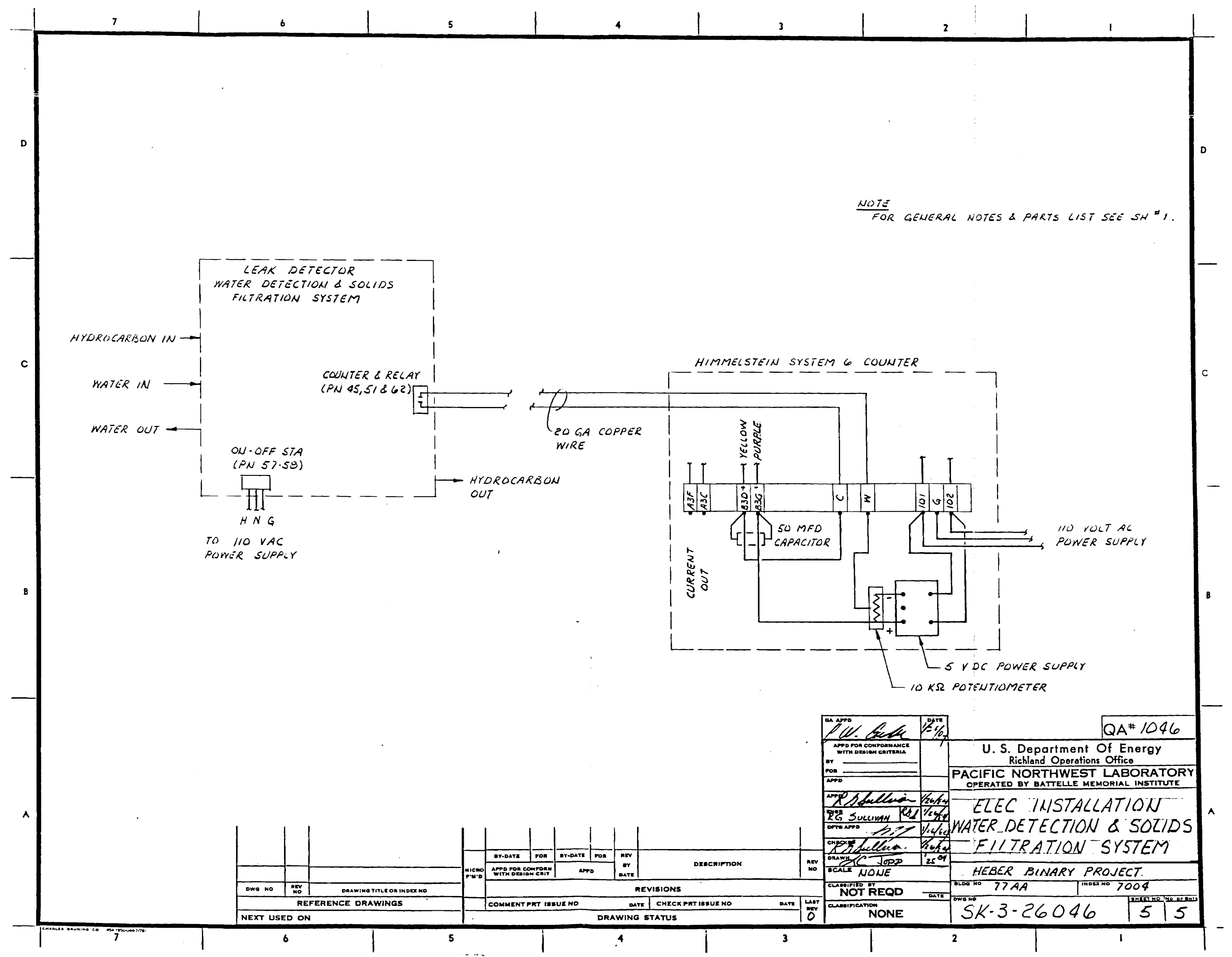




\subsection{LIST OF OTHER MANUALS}

The following manuals have been written by other equipment manufacturers who supplied electronic parts for the complete leak detector system. They are bound separately but should all be kept together.

1. S. Himmelstein and Company

1.0 System Operation

2.0 System 6 Data

3.0 Not applicable

4.0 Recommended spare parts

5.0 Circuit documentation

6.0 Reference material

2. Drexelbrook Engineering Company

1.0 Installation and operating instructions for Series 508-25, $-26,-27,-29$. Two wire level transmitter using 408-6200 Cote-Shield Electronics.

2.0 Installation and operating instructions for "Setcon" 401-1000 series. 


\section{DISTRIBUTION}

No. of

Copies

\section{OFFSITE}

2 DOE Technical Information

Center

5 David Allen

Mailstop 5G-046-C

Geothermal/Hydrothermal Techno1ogy Division

U.S. Department of Energy

1000 Independence SW

Washington, D.C. 20585

5 A. J. Adduci

U.S. Department of Energy

San Francisco Operations Office

1333 Broadway

Oakland, California 94612

2 Paul L. Thrash

U.S. Department of Energy

San Francisco Operations Office

1333 Broadway

Oakland, California 94612

10 Mr. Tiff Nelson

San Diego Gas \& Electric Company

P.O. Box 1831

San Diego, California 92112

\section{ONSITE}

DOE Richland Operations Office

H. E. Ransom

21 Pacific Northwest Laboratory

R. L. Clark

C. R. Hann

C. H. Kindle

D. D. Pierce

K. H. Pool

R. J. Robertus (10)

D. W. Shannon

R. G. Sullivan

Publishing Coordination

Technical Information (3) 